\title{
Development of a Gradient HPLC Method for the Simultaneous Determination of Sotalol and Sorbate in Oral Liquid Preparations Using Solid Core Stationary Phase
}

\author{
Ludmila Matysova, ${ }^{1}$ Oxana Zahalkova, ${ }^{1}$ Sylva Klovrzova,, ${ }^{2,3}$ Zdenka Sklubalova, ${ }^{2}$ \\ Petr Solich, ${ }^{1}$ and Lukas Zahalka ${ }^{1}$ \\ ${ }^{1}$ Department of Analytical Chemistry, Faculty of Pharmacy in Hradec Kralove, Charles University in Prague, \\ 50005 Hradec Kralove, Czech Republic \\ ${ }^{2}$ Department of Pharmaceutical Technology, Faculty of Pharmacy in Hradec Kralove, Charles University in Prague, \\ 50005 Hradec Kralove, Czech Republic \\ ${ }^{3}$ Hospital Pharmacy, University Hospital in Motol, 15006 Prague 5, Czech Republic
}

Correspondence should be addressed to Petr Solich; solich@faf.cuni.cz

Received 13 January 2015; Revised 10 March 2015; Accepted 10 March 2015

Academic Editor: Sibel A. Ozkan

Copyright (C) 2015 Ludmila Matysova et al. This is an open access article distributed under the Creative Commons Attribution License, which permits unrestricted use, distribution, and reproduction in any medium, provided the original work is properly cited.

\begin{abstract}
A selective and sensitive gradient HPLC-UV method for quantification of sotalol hydrochloride and potassium sorbate in five types of oral liquid preparations was developed and fully validated. The separation of an active substance sotalol hydrochloride, potassium sorbate (antimicrobial agent), and other substances (for taste and smell correction, etc.) was performed using an Ascentis Express C18 $(100 \times 4.6 \mathrm{~mm}$, particles $2.7 \mu \mathrm{m})$ solid core HPLC column. Linear gradient elution mode with a flow rate of $1.3 \mathrm{~mL} \mathrm{~min}^{-1}$ was used, and the injection volume was $5 \mu \mathrm{L}$. The UV/Vis absorbance detector was set to a wavelength of $237 \mathrm{~nm}$, and the column oven was conditioned at $25^{\circ} \mathrm{C}$. A sodium dihydrogen phosphate dihydrate solution ( $\mathrm{pH} 2.5 ; 17.7 \mathrm{mM}$ ) was used as the mobile phase buffer. The total analysis time was $4.5 \mathrm{~min}$ ( $+2.5 \mathrm{~min}$ for reequilibration). The method was successfully employed in a stability evaluation of the developed formulations, which are now already being used in the therapy of arrhythmias in pediatric patients; the method is also suitable for general quality control, that is, not only just for extemporaneous preparations containing the mentioned substances.
\end{abstract}

\section{Introduction}

Sotalol (SOT) is a Class III antiarrhythmic agent that prolongs the QT interval and exhibits beta-adrenergic blocking properties. SOT has been widely used in the management of atrial arrhythmias for several decades including patients in the pediatric age group and those with congenital heart disease. In pediatric patients, SOT has proven efficacy in suppressing supraventricular arrhythmias and maintaining a sinus rhythm with recurrence-free intervals of $>80 \%$ and has also been used in the management of ventricular arrhythmias with more modest efficacy [1].

Potassium sorbate (SORB) is an antimicrobial preservative with antibacterial and antifungal properties and is used in pharmaceuticals, foods, enteral preparations, and cosmetics.
In general, SORB is used at concentrations of $0.1-0.2 \%$ in oral and topical formulations. Potassium sorbate is used in approximately twice as many pharmaceutical formulations as sorbic acid due to its greater solubility and stability in water. As with sorbic acid, potassium sorbate exhibits minimal antibacterial properties in formulations with $\mathrm{pH}$ values higher than 6 [2].

There are no registered medicinal products containing sotalol suitable for administration in pediatric patients and available in the European Union (EU) member states and selected non-EU countries (Supplement) (see Supplementary Material available online at http://dx.doi.org/10.1155/2015/ 806736) [3]. Pediatric formulations have many specific characteristics. The most important one is the ability to administer dosages of an active substance in variable and precise 
amounts according to the actual weight of a child. In addition, the dosage form has to be easily swallowed $[4,5]$. When no appropriate dosage form is commercially available, the most suitable alternative is the use of oral liquid extemporaneous preparations with an antimicrobial agent for older children and with no antimicrobial agent for infants. The cooperation between the Department of Pharmaceutical Technology (Charles University, Faculty of Pharmacy, Hradec Kralove) and the Hospital Pharmacy (University Hospital in Motol, Prague) has led to the development of five versions of oral liquid preparations with sotalol hydrochloride as the active substance and potassium sorbate as the preservative. The HPLC determination of sotalol has been previously reported [6-10], but the simultaneous determination of sotalol and sorbate in various matrices (e.g., sirupus simplex $\sim$ sucrose syrup, saccharine, and citric acid) in a liquid dosage has not been previously published. The aim of this study was to develop and validate a selective and rapid method using standard HPLC system for the determination of sotalol hydrochloride (i.e., the active substance) and potassium sorbate (i.e., the antimicrobial agent) and their separation from other present substances in newly developed pediatric oral preparations and its application for stability study. In order to achieve total separation of sotalol, sorbate, and other analytes that possess different chromatographic properties at the lowest possible analysis time at standard HPLC system, modern solid core columns and gradient elution were adopted during method development.

Columns of solid core particles exhibit unusual chromatographic efficiency. Presumably, this is due to the ability to form very homogeneous packed beds as a result of an extremely narrow particle size distribution and higher particle density. Solid core particles exhibit highly improved mass transfer (kinetic) effects because of the thin porous shell surrounding a solid core, allowing solutes to rapidly diffuse in and out of the porous structure containing the stationary phase for interaction. Columns of the solid core particles $(2.7 \mu \mathrm{m})$ exhibit theoretical plates nearly comparable to those of sub-2-micron totally porous particles, but with much reduced pressure requirements and thus it is possible to use them at standard HPLC systems [11].

\section{Materials and Methods}

2.1. Materials and Chemicals. Sotalol hydrochloride (Fagron, Olomouc, Czech Republic) and potassium sorbate (Dr. Kulich Pharma, Hradec Kralove, Czech Republic) were used as the standards. Ethylparaben (Sigma-Aldrich, Steinheim, Germany) was used as an internal standard (IS). Sodium dihydrogen phosphate dihydrate (Sigma-Aldrich, Steinheim, Germany), orthophosphoric acid (Merck, Darmstadt, Germany), acetonitrile (ACN) gradient grade (Sigma-Aldrich, Steinheim, Germany), methanol $(\mathrm{MeOH})$ gradient grade (SigmaAldrich, Steinheim, Germany), and tetrahydrofuran (THF) Chromasolv (Sigma-Aldrich, Steinheim, Germany) were used to prepare the mobile phase. Water for the sample and mobile phase preparation was purified by Milli-Q Integral 15 system with $0.22 \mu \mathrm{m}$ output filter. Nylon membrane filters
TABLE 1: Linear gradient.

\begin{tabular}{lcc}
\hline$T[\mathrm{~min}]$ & $\% A$ (buffer) & $\% B(\mathrm{ACN})$ \\
\hline 0.00 & 90 & 10 \\
4.00 & 40 & 60 \\
4.49 & 40 & 60 \\
4.50 & 90 & 10 \\
7.00 & 90 & 10 \\
\hline
\end{tabular}

$(0.20 \mu \mathrm{m})$ were used for mobile phase filtration (Albet, Dassel, Germany). Nylon membrane filters $(0.22 \mu \mathrm{m})$ (Vitrum, Prague, Czech Republic) and $2 \mathrm{~mL}$ syringes (Chirana T. Injecta, Stara Tura, Slovak Republic) were used to filter the samples. A $1000 \mu \mathrm{L}$ Transferpette micropipette (Brand, Wertheim, Germany) was used. Formulations F1-F5 (and respective blank solutions), which contain sotalol hydrochloride $\left(5 \mathrm{mg} \mathrm{mL}^{-1}\right)$, potassium sorbate $\left(1 \mathrm{mg} \mathrm{mL}^{-1}\right)$, and excipients (e.g., water for injection, sirupus simplex, citric acid, disodium hydrogen phosphate dodecahydrate, and sodium saccharine), were obtained as extemporaneous preparations from the Hospital Pharmacy at the University Hospital in Motol, Prague, Czech Republic.

2.2. Instrumentation and Chromatographic Conditions. The chromatographic analysis was performed on an integral system Shimadzu LC-2010C (Shimadzu, Kyoto, Japan). The following chromatographic columns were tested during method development: Ascentis Express C18 $(150 \times 4.6 \mathrm{~mm}$, particles $2.7 \mu \mathrm{m})$, Ascentis Express C18 $(100 \times 4.6 \mathrm{~mm}$, particles $2.7 \mu \mathrm{m})$, and Ascentis Express Phenyl-Hexyl $(100 \times 4.6 \mathrm{~mm}$, particles $5 \mu \mathrm{m})$. An Ascentis Express C18 $(100 \times 4.6 \mathrm{~mm}$, particles $2.7 \mu \mathrm{m}$ ) column was finally chosen for the method validation and stability testing. The dual absorbance UV/Vis detector was set to a wavelength of $237 \mathrm{~nm}$. Linear gradient elution (Table 1) with a flow rate of $1.3 \mathrm{~mL} \mathrm{~min}^{-1}$ was used. A column oven was conditioned at $25^{\circ} \mathrm{C}$. The injection volume was $5 \mu \mathrm{L}$ and analysis time was 4.5 minutes $(7$ minutes with reequilibration time incl.).

2.3. Preparation of Buffer Component of Mobile Phase (Approximately 1L). $2.76 \mathrm{~g}$ of sodium dihydrogen phosphate dihydrate was dissolved in $1 \mathrm{~L}$ of ultrapure water. An orthophosphoric acid solution (6\%) was used to adjust the $\mathrm{pH}$ to $2.5( \pm 0.05)$. The mobile phase buffer was filtered through a nylon membrane filter $(0.20 \mu \mathrm{m})$ using a Millipore glass filter holder. The mobile phase buffer was used immediately after preparation or stored in the refrigerator in closed borosilicate glass bottles for a maximum of 24 hours.

2.4. Preparation of Stock, IS, Standard, Sample, and Blank Solutions. The preparation of the stock, IS, standard, sample, and blank solutions is described in Table 2.

\section{Results and Discussion}

3.1. Method Development. The initial chromatographic conditions and mobile phase composition were chosen to be 
TABLE 2: Stock, IS, standard, sample, and blank solutions preparation.

\begin{tabular}{|c|c|c|c|c|c|}
\hline Composition and process & $\begin{array}{c}\text { Stock } \\
\text { solution of } \\
\text { standards }\end{array}$ & $\begin{array}{c}\text { Stock } \\
\text { solution of IS }\end{array}$ & $\begin{array}{l}\text { Standard } \\
\text { solution }\end{array}$ & $\begin{array}{l}\text { Sample } \\
\text { solution }\end{array}$ & $\begin{array}{l}\text { Blank } \\
\text { solution }\end{array}$ \\
\hline Sotalol hydrochloride & $\sim 100.00 \mathrm{mg}$ & - & - & - & - \\
\hline Potassium sorbate & $\sim 20.00 \mathrm{mg}$ & - & - & - & - \\
\hline Ethylparaben & - & $\sim 100.00 \mathrm{mg}$ & - & - & - \\
\hline Stock solution of standards & - & - & $1.000 \mathrm{~mL}$ & - & - \\
\hline Stock solution of IS & - & - & $1.000 \mathrm{~mL}$ & $1.000 \mathrm{~mL}$ & - \\
\hline Oral preparation (SOT $5 \mathrm{mg} \mathrm{mL}^{-1}$ ) & - & - & - & $1.000 \mathrm{~mL}$ & - \\
\hline Placebo of preparation (neither SOT nor SORB) & - & - & - & - & $1.000 \mathrm{~mL}$ \\
\hline Dissolvent $\mathrm{ACN}$ : water & $50: 50(\mathrm{v} / \mathrm{v})$ & $50: 50(\mathrm{v} / \mathrm{v})$ & $30: 70(\mathrm{v} / \mathrm{v})$ & $30: 70(\mathrm{v} / \mathrm{v})$ & $30: 70(\mathrm{v} / \mathrm{v})$ \\
\hline Total volume & $20.00 \mathrm{~mL}$ & $50.00 \mathrm{~mL}$ & $25.00 \mathrm{~mL}$ & $25.00 \mathrm{~mL}$ & $25.00 \mathrm{~mL}$ \\
\hline Membrane filtration $0.22 \mu \mathrm{m}$ & - & - & Yes & Yes & Yes \\
\hline Injection to the column & - & - & Yes $(5 \mu \mathrm{L})$ & Yes $(5 \mu \mathrm{L})$ & Yes $(5 \mu \mathrm{L})$ \\
\hline
\end{tabular}

similar to those used by Delamoye et al. for the separation of thirteen $\beta$-blockers [12]. C18 stationary phase column with solid core $2.7 \mu \mathrm{m}$ particles, $4.6 \mathrm{~mm}$ i.d., and $100 \mathrm{~mm}$ length was initially tested. A mobile phase consisting of sodium dihydrogen phosphate dihydrate ( $\mathrm{pH} 3.8 ; 17.7 \mathrm{mM})$ ACN $(65: 35, \mathrm{v} / \mathrm{v})$ did not provide separation of the sotalol peak from the dead volume peak. An increase in the phosphate buffer ( $\mathrm{pH} 3.8 ; 17.7 \mathrm{mM}$ ) component led to a desirable increase in the sotalol retention. Phosphate buffer (pH 3.8; $17.7 \mathrm{mM})-\mathrm{ACN}(80: 20$ and $85: 15, \mathrm{v} / \mathrm{v})$ only provided partial separation of sotalol from the dead volume peak. Phosphate buffer ( $\mathrm{pH} 3.8 ; 17.7 \mathrm{mM})$-ACN $(90: 10$, v/v) was sufficient for proper sotalol retention. The addition of THF was tested to observe possible positive effects on peak shape. Unfortunately, THF addition did not provide any advantages and led to a rapid increase in the baseline noise and drift. The use of $\mathrm{MeOH}$ instead of acetonitrile also led to a less stable baseline as well as an undesirable increase in the system back pressure. Avoiding the phosphate buffer and using only ACN-water mobile phases caused unacceptable peak fronting and tailing. Therefore, the buffer is necessary for maintaining good peak shapes and separation. Isocratic elution with the phosphate buffer ( $\mathrm{pH} 3.8 ; 17.7 \mathrm{mM})$-ACN (90:10, v/v) mobile phase cannot be used due to a significant increase in the analysis time caused by different retention properties of sotalol (base) and sorbate (acid). Under acidic conditions sotalol is in ionized form and thus it is not well retained on the stationary phase; opposite sorbate is in nonionized form and it is therefore significantly retained on the column. Different gradient curve profiles were tested, and a linear gradient was chosen because it resulted in the lowest baseline drift. A terminal gradient concentration of ACN was tested up to $70 \%$, but a maximum usable concentration of $60 \%$ was required to maintain a straight baseline. Gradient elution with initial phosphate buffer ( $\mathrm{pH} 3.8 ; 17.7 \mathrm{mM}$ )-ACN (from $90: 10$ to $40: 60, \mathrm{v} / \mathrm{v}$ ) could be used for the separation of sotalol and sorbate. Unfortunately, these conditions cannot be used for analysis of preparations containing the artificial sweetener saccharine (SACC) due to its coelution with the sotalol peak. An increase in the temperature up to $60^{\circ} \mathrm{C}$ or the use of an Ascentis Express Phenyl-Hexyl column did not provide any favorable changes in the selectivity and using of Ascentis Express C18 $(150 \times 4.6 \mathrm{~mm}, 2.7 \mu \mathrm{m}$ particles $)$ also did not provide sufficient SOT-SACC separation. An elevated temperature resulted even in a decreased resolution of the SOT and SACC peaks. Several buffer $\mathrm{pH}$ values $(4.6 ; 3.8 ; 3.0$; 2.5; and 2.0) were tested (Figure 1). Using 4.6 or $3.8 \mathrm{pH}$ buffers caused coelution of SOT/SACC, $\mathrm{pH} 3.0$ buffer provided reasonable separation of the SOT/SACC peaks (resolution = 1.44), and finally the 2.5 buffer led to complete separation of the mentioned analytes to the baseline (resolution > 1.5). The $\mathrm{pH} 2.0$ buffer also provided total SOT/SACC separation but it is not recommended due to an expected decrease in the column lifetime. These experimental results correspond to the theoretical useful $\mathrm{pH}$ range of phosphate buffer which is 2.1-3.1 [13]. Methylparaben, ethylparaben, propylparaben, butylparaben, paracetamol, and salicylic acid were tested as possible internal standards (IS). Paracetamol was coeluted with the dead volume peak, methylparaben and salicylic acid were not sufficiently separated from the sorbate peak, and propylparaben with butylparaben was eluted with unfavorable long retention times. Ethylparaben was finally chosen as the IS because it is stable in solution, inexpensive, and well separated from all of the analytes in the oral preparations. In addition, ethylparaben exhibits good UV absorption in UV. Various concentrations of the sample solution and injection volumes were tested to ensure a suitable tailing factor and sufficient response (absorbance). The UV spectra of sotalol and sorbate were obtained with a $\mathrm{UV} / \mathrm{Vis} \mathrm{DAD}$ spectrophotometer, and the tested wavelengths of the UV/Vis absorbance HPLC detector ranged from 200 to $300 \mathrm{~nm}$. Finally, the wavelength was set to $237 \mathrm{~nm}$ to ensure good sensitivity, as well as low baseline noise.

3.2. Sample Preparation Development. The simple method known as "dilute and shoot" was used for sample preparation. The pharmaceutical preparation was diluted 25 times (i.e., $1.000 \mathrm{~mL}$ of the preparation with $1.000 \mathrm{~mL}$ of the IS stock 


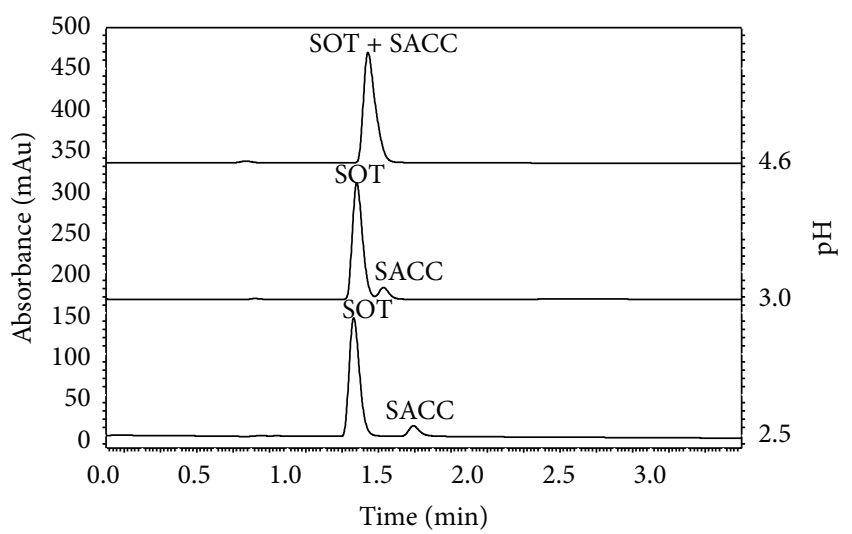

Figure 1: Significance of mobile phase buffer $\mathrm{pH}$ controlling in SOT/SACC separation; pharmaceutical formulation F4 $(1.000 \mathrm{~mL}$ of pharmaceutical preparation diluted to $25.00 \mathrm{~mL}$ ); injection volume $5 \mu \mathrm{L}$; mobile phase flow $1.3 \mathrm{~mL} \mathrm{~min}^{-1}$; linear gradient (ACN: $10 \%$ to $60 \%$ in 4 minutes); UV/Vis detector wavelength $237 \mathrm{~nm}$; column oven $25^{\circ} \mathrm{C}$.

solution was diluted to $25.00 \mathrm{~mL}$ with a mixture of ACNwater $(30: 70, \mathrm{v} / \mathrm{v}))$ to avoid previously reported matrix effects of the liquid pharmaceutical formulations [14]. The standard solution was prepared in the same way as the sample solution using a stock solution of the standards. The concentration of SOT, SORB, and EP was selected to ensure the same concentration level in the sample and standard solutions. An increase in the ACN component (e.g., to 50\%) led to rapid deterioration of the peak shapes, especially significant fronting of the SOT and SACC peaks. Therefore, an ACN concentration higher than $30 \%$ is not practical.

3.3. Method Validation. The method was validated according to ICH Q2 (R1) guidelines [15]. The system suitability (i.e., repeatability of retention times and areas, number of theoretical plates, resolution, and tailing factor), precision, linearity, accuracy, selectivity, and robustness were evaluated during method validation (Table 3). The parameters accuracy, precision, and selectivity were performed and evaluated for all five pharmaceutical formulations.

3.3.1. System Suitability Test (SST). SST was performed on a standard solution that was injected into the column six times. The reported values are arithmetic means of six injections.

3.3.2. Precision. Six sample solutions were prepared from each of the five preparations. Each sample was injected three times. The final results are reported as relative standard deviations (R.S.D.) of the SOT/EP and SORB/EP ratios of the peak areas.

3.3.3. Linearity. A calibration curve was created using 6 points that covered the concentration range of sotalol hydrochloride from $0.1 \mathrm{mg} \mathrm{mL}^{-1}$ to $0.4 \mathrm{mg} \mathrm{mL}^{-1}$ and potassium sorbate from $0.02 \mathrm{mg} \mathrm{mL}^{-1}$ to $0.08 \mathrm{mg} \mathrm{mL}^{-1}$. Linear regression was used to process the calibration data. The correlation

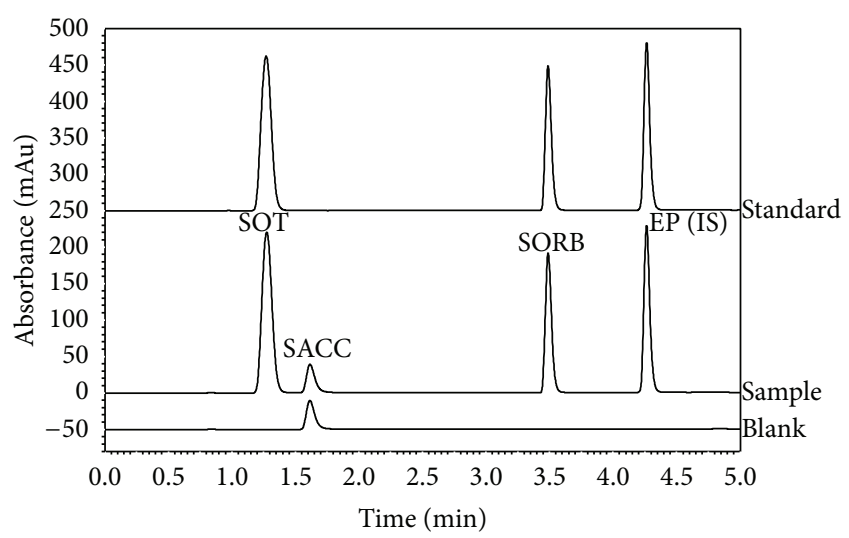

FIgure 2: Chromatograms of the standard solution (SOT $0.2 \mathrm{mg} \mathrm{mL}^{-1}$, SORB $0.04 \mathrm{mg} \mathrm{mL}^{-1}$, and EP $0.08 \mathrm{mg} \mathrm{mL}^{-1}$ ), sample solution $(1.000 \mathrm{~mL}$ of pharmaceutical preparation and $1.000 \mathrm{~mL}$ of stock solution of internal standard EP diluted to $25.00 \mathrm{~mL}$ ), and blank solution ( $1.000 \mathrm{~mL}$ of placebo diluted to $25.00 \mathrm{~mL}$ ); injection volume $5 \mu \mathrm{L}$; mobile phase flow $1.3 \mathrm{~mL} \mathrm{~min}^{-1}$; linear gradient (ACN: $10 \%$ to $60 \%$ in 4 minutes); UV/Vis detector wavelength $237 \mathrm{~nm}$; column oven $25^{\circ} \mathrm{C}$.

coefficients of linearity were 0.9995 for sotalol hydrochloride and 0.9995 for potassium sorbate, which indicate good correlation between the peak areas and the range of concentrations studied.

3.3.4. Accuracy. The solutions for injection were prepared using a placebo and stock solution of standards instead of the oral preparation. Six solutions were prepared from each of the five preparations. Each solution was injected onto the column three times. Accuracy is reported as a parameter recovery with relative standard deviations.

3.3.5. Selectivity. The selectivity was determined by comparing the chromatograms of sample solutions, standard solution, and blank solutions. Figure 2 shows that sotalol hydrochloride (i.e., the active substance), potassium sorbate (i.e., antimicrobial agent), and ethylparaben (i.e., internal standard) are all completely separated from each other and from the saccharine peak both in the standard solution and in the sample solution. No interference was observed.

3.3.6. Robustness. Various buffer $\mathrm{pH}$ values and compositions of the mobile phase were tested. A mobile phase buffer with a $\mathrm{pH}$ ranging from 2.3 to 2.7 was used without remarkable changes in the accuracy (98.99-100.37\%). A sodium dihydrogen phosphate dihydrate $(\mathrm{pH} 2.5 ; 17.7 \mathrm{mM})-\mathrm{ACN}$ initial gradient ratio ranging from $92: 8$ to $89: 11(\mathrm{v} / \mathrm{v})$ was used without remarkable changes in the accuracy (97.42$100.70 \%)$. However, the $88: 12$ ratio led to higher fluctuations in the retention times, and, therefore, this ratio is not recommended. All of the tested ratios ensured complete separation to the baseline for all of these compounds. The stability of the standard solution was tested at room temperature without light protection and at $5 \pm 3^{\circ} \mathrm{C}$ light protected 24,48 , and 72 hours after its preparation. The accuracy of the peak areas for 
TABLE 3: Validation parameters of formulations F1-F5.

\begin{tabular}{|c|c|c|c|c|c|c|c|c|c|c|c|}
\hline & \multicolumn{2}{|c|}{$\mathrm{F} 1$} & \multicolumn{2}{|c|}{$\mathrm{F} 2$} & \multicolumn{2}{|c|}{ F3 } & \multicolumn{2}{|c|}{$\mathrm{F} 4$} & \multicolumn{2}{|c|}{ F5 } & \multirow{2}{*}{ Criterion } \\
\hline & SOT & SORB & SOT & SORB & SOT & SORB & SOT & SORB & SOT & SORB & \\
\hline $\begin{array}{l}\text { Repeatability } t_{R}(\% \\
\text { R.S.D. })^{\mathrm{a}}\end{array}$ & 0.00 & 0.00 & 0.00 & 0.00 & 0.00 & 0.00 & 0.00 & 0.00 & 0.00 & 0.00 & $X<1 \%$ \\
\hline $\begin{array}{l}\text { Repeatability area (\% } \\
\text { R.S.D.) }{ }^{\mathrm{a}}\end{array}$ & 0.22 & 0.57 & 0.22 & 0.57 & 0.22 & 0.57 & 0.22 & 0.57 & 0.22 & 0.57 & $X<1 \%$ \\
\hline $\begin{array}{l}\text { Theoretical plates per } \\
\text { meter }\end{array}$ & 11,810 & 282,650 & 11,810 & 282,650 & 11,810 & 282,650 & 11,810 & 282,650 & 11,810 & 282,650 & - \\
\hline Resolution $^{\mathrm{a}}$ & - & 18.39 & - & 18.39 & - & 18.39 & - & 18.39 & - & 18.39 & $R_{i j}>1.5$ \\
\hline Tailing factor ${ }^{\mathrm{a}}$ & 1.10 & 1.23 & 1.10 & 1.23 & 1.10 & 1.23 & 1.10 & 1.23 & 1.10 & 1.23 & $T=0.8-1.5$ \\
\hline Precision (\% R.S.D. $)^{\mathrm{b}}$ & 0.43 & - & 0.16 & - & 0.49 & 0.98 & 0.26 & 1.51 & 0.21 & 1.11 & $X<5 \%$ \\
\hline $\begin{array}{l}\text { Linearity (correlation } \\
\text { coefficient) }^{c}\end{array}$ & 0.9995 & 0.9995 & 0.9995 & 0.9995 & 0.9995 & 0.9995 & 0.9995 & 0.9995 & 0.9995 & 0.9995 & $R>0.9990$ \\
\hline Accuracy recovery $(\%)^{\mathrm{b}}$ & 101.09 & - & 99.57 & - & 99.59 & 98.26 & 99.93 & 98.70 & 99.35 & 98.57 & $X=100 \pm 5 \%$ \\
\hline Accuracy (\% R.S.D. $)^{b}$ & 0.58 & - & 0.85 & - & 1.44 & 2.27 & 0.71 & 2.07 & 0.57 & 1.14 & $X<5 \%$ \\
\hline Selectivity & \multicolumn{2}{|c|}{ No interference } & \multicolumn{2}{|c|}{ No interference } & \multicolumn{2}{|c|}{ No interference } & \multicolumn{2}{|c|}{ No interference } & \multicolumn{2}{|c|}{ No interference } & No interference \\
\hline
\end{tabular}

${ }^{a}$ Six injections.

${ }^{\mathrm{b}}$ Six samples, three injections of each sample.

${ }^{c}$ At 50, 75, 100, 134, 166, and 200\% concentration levels.

SOT: sotalol hydrochloride.

SORB: potassium sorbate.

Fx: formulations with various excipients.

$\%$ R.S.D.: relative standard deviation in \%.

both storage conditions during the entire 72 hours was $99.32-$ $100.62 \%$.

\section{Conclusions}

The optimal chromatographic conditions for separation of an active substance sotalol hydrochloride, potassium sorbate, and other substances were achieved on an Ascentis Express C18 $(100 \times 4.6 \mathrm{~mm}$, particles $2.7 \mu \mathrm{m})$ solid core particles column and with a linear gradient elution at a flow rate of $1.3 \mathrm{~mL} \mathrm{~min}^{-1}$, using $\mathrm{pH} 2.5$ phosphate buffer-ACN mixture (ACN 10-60\%) as mobile phase and detection set to a wavelength of $237 \mathrm{~nm}$. The method is rapid with a total analysis time of 4.5 minutes ( +2.5 minutes of reequilibration). The sample preparation is a simple "dilute and shoot" method using an internal standard (ethylparaben). All measured parameters of the validation demonstrate the suitability of this new HPLC method for the analysis of oral liquid pharmaceutical preparations containing the above substances. The method was successfully employed in a stability evaluation of the four developed formulations with different composition, which are now already being used in the therapy of arrhythmias in pediatric patients. The method is also suitable for general quality control, that is, not only just for extemporaneous preparations containing the mentioned substances.

\section{Conflict of Interests}

The authors declare that there is no conflict of interests regarding the publication of this paper.

\section{Acknowledgments}

The authors gratefully acknowledge financial support by the Charles University in Prague (GAUK 1472213), the Czech Ministry of Education, Youth and Sports (SVV 260 183, SVV 260 184), and the MH CZ-DRO, University Hospital in Motol, Prague, Czech Republic (00064203). The paper is cofinanced by the European Social Fund and the State Budget of the Czech Republic, TEAB, Project no. CZ.1.07/2.3.00/ 20.0235 .

\section{References}

[1] L. Harris and K. Nair, "Arrhythmia management: advances and new perspectives in pharmacotherapy in congenital heart disease," Progress in Pediatric Cardiology, vol. 34, no. 2, pp. 6973, 2012.

[2] R. C. Rowe, P. J. Sheskey, and M. E. Quinn, Handbook of Pharmaceutical Excipients, 6th edition, 2009.

[3] National competent authorities for human medicines, Medicinal products databases, available online.

[4] J. F. Standing and C. Tuleu, "Paediatric formulations - getting to the heart of the problem," International Journal of Pharmaceutics, vol. 300, no. 1-2, pp. 56-66, 2005.

[5] T. Nunn and J. Williams, "Formulation of medicines for children," British Journal of Clinical Pharmacology, vol. 59, no. 6, pp. 674-676, 2005.

[6] R. G. Morris, "Improved liquid chromatographic fluorescence method for estimation of plasma sotalol concentrations," Therapeutic Drug Monitoring, vol. 11, no. 1, pp. 63-66, 1989. 
[7] M. J. Bartek, M. Vekshteyn, M. P. Boarman, and D. G. Gallo, "Liquid chromatographic determination of sotalol in plasma and urine employing solid-phase extraction and fluorescence detection," Journal of Chromatography, vol. 421, no. 2, pp. 309318, 1987.

[8] I. Baranowska and A. Wilczek, "Simultaneous RP-HPLC determination of sotalol, metoprolol, alpha-hydroxymetoprolol, paracetamol and its glucuronide and sulfate metabolites in human urine," Analytical Sciences, vol. 25, no. 6, pp. 769-772, 2009.

[9] S. Läer, I. Wauer, and H. Scholz, "Small blood volumes from children for quantitative sotalol determination using highperformance liquid chromatography," Journal of Chromatography B: Biomedical Sciences and Applications, vol. 753, no. 2, pp. 421-425, 2001.

[10] B. Lemmer, T. Ohm, and H. Winkler, "Determination of the beta-adrenoceptor blocking drug sotalol in plasma and tissues of the rat by high-performance liquid chromatography with ultraviolet detection," Journal of Chromatography B: Biomedical Sciences and Applications, vol. 309, no. 1, pp. 187-192, 1984.

[11] J. J. DeStefano, T. J. Langlois, and J. J. Kirkland, "Characteristics of superficially-porous silica particles for fast HPLC: some performance comparisons with sub-2- $\mu \mathrm{m}$ particles," Journal of Chromatographic Science, vol. 46, no. 3, pp. 254-260, 2008.

[12] M. Delamoye, C. Duverneuil, F. Paraire, P. de Mazancourt, and J.-C. Alvarez, "Simultaneous determination of thirteen $\beta$ blockers and one metabolite by gradient high-performance liquid chromatography with photodiode-array UV detection," Forensic Science International, vol. 141, no. 1, pp. 23-31, 2004.

[13] A. N. Heyrman and A. R. Henry, "Importance of controlling mobile phase $\mathrm{pH}$ in reversed phase HPLC," Keystone Technical Bulletin TB 99-06, 1999.

[14] L. Zahálka, L. Matysová, Z. Šklubalová, S. Klovrzová, and P. Solich, "Simultaneous determination of propranolol hydrochloride and sodium benzoate in oral liquid preparations by HPLC," Chromatographia, vol. 76, no. 21-22, pp. 1553-1558, 2013.

[15] ICH Expert Working Group, Validation of Analytical Procedures: Text and Methodology Q2(R1), 2005, http://www.ich.org/ fileadmin/Public_Web_Site/ICH_Products/Guidelines/Quality/ Q2_R1/Step4/Q2_R1__Guideline.pdf. 

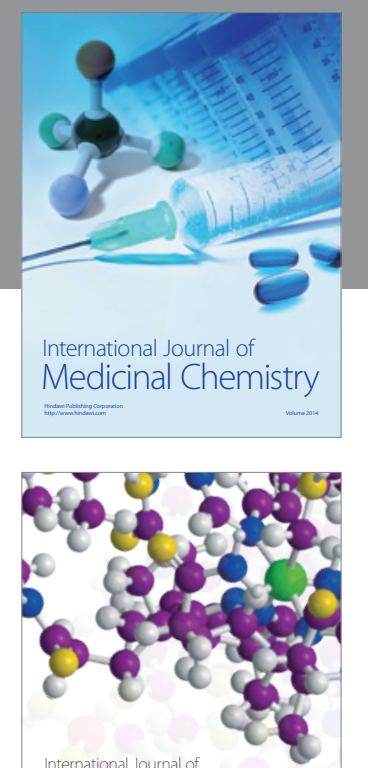

\section{Carbohydrate} Chemistry

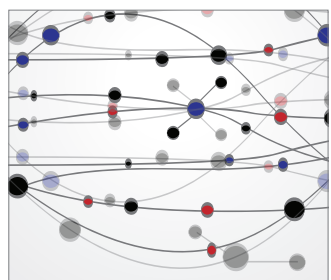

The Scientific World Journal
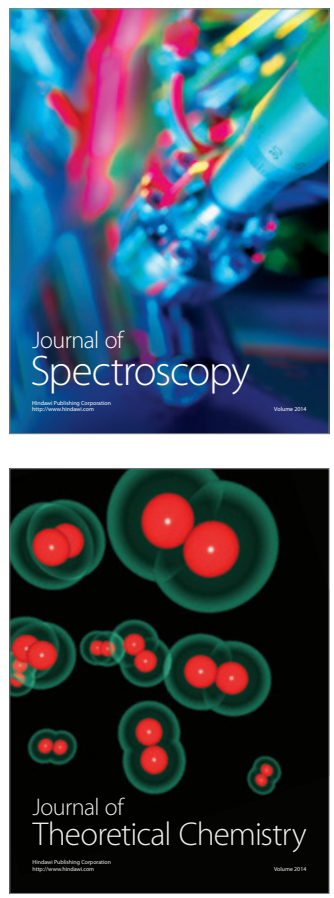
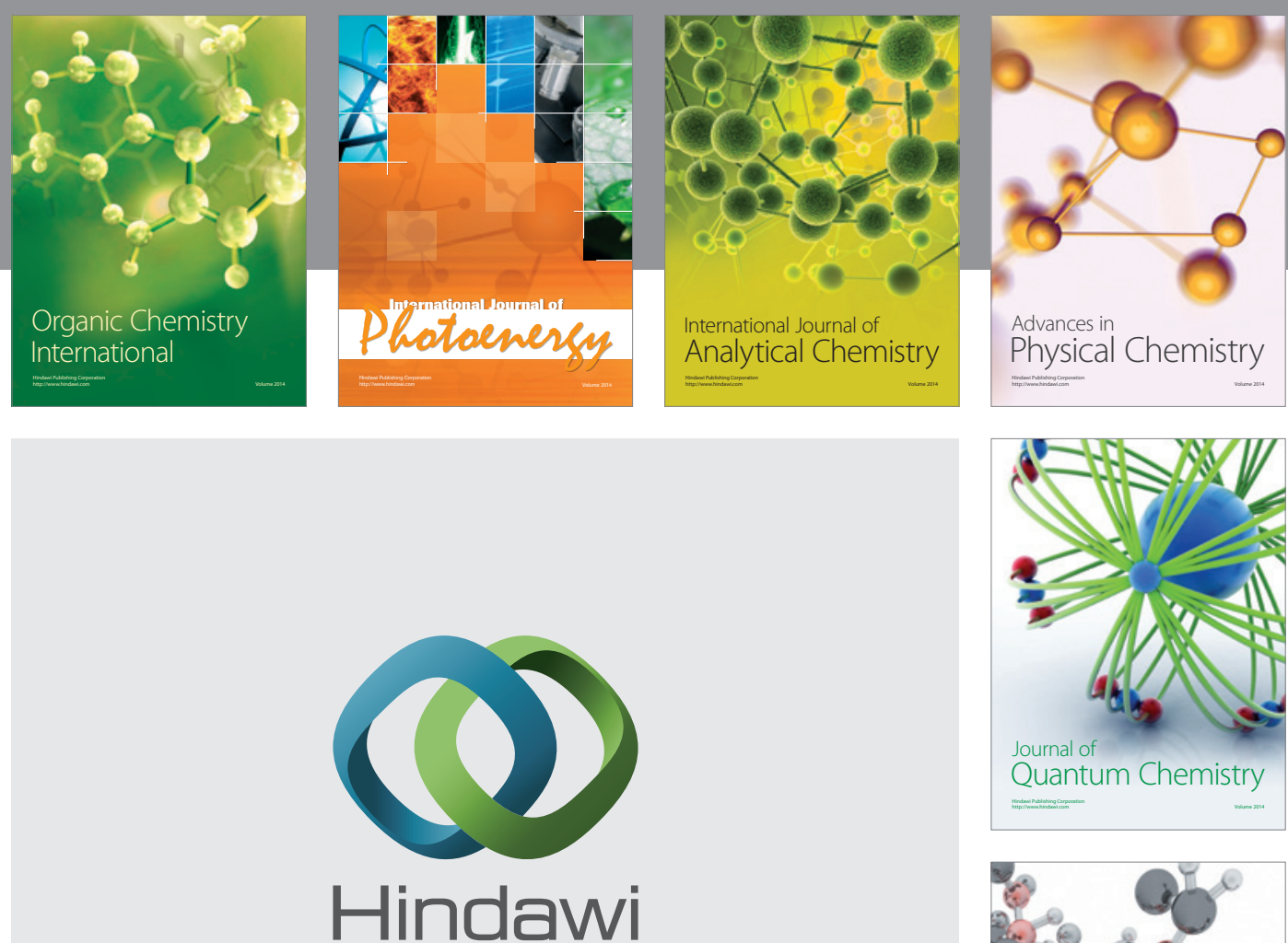

Submit your manuscripts at

http://www.hindawi.com

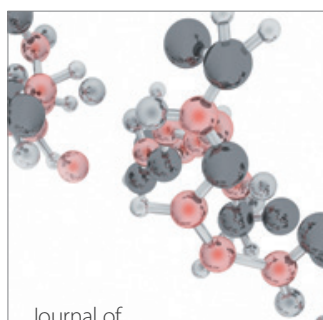

Analytical Methods

in Chemistry

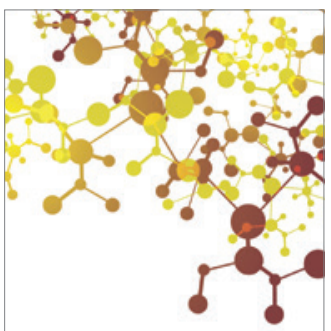

Journal of

Applied Chemistry

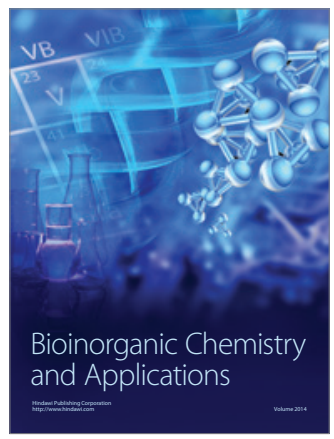

Inorganic Chemistry
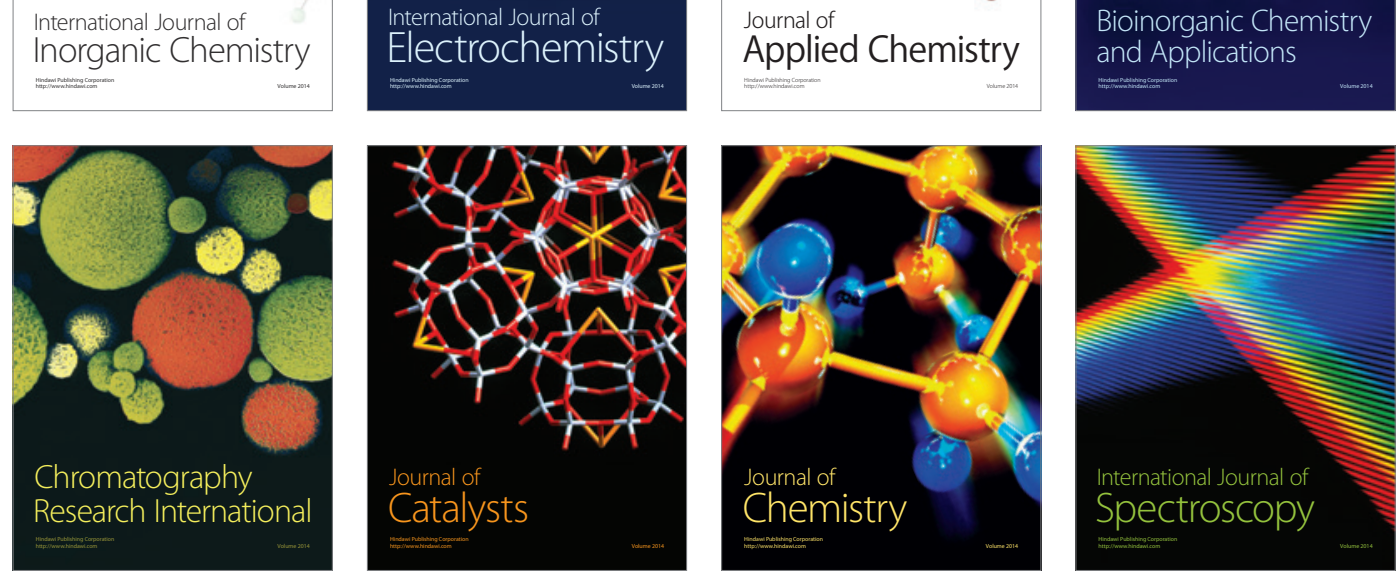